\title{
Clavispora lusitaniae
}

National Cancer Institute

\section{Source}

National Cancer Institute. Clavispora lusitaniae. NCI Thesaurus. Code C77174.

A species of yeast in the genus Candida. 